Research Article

\title{
Structural Damage of Subway Tunnel Buried Shallowly in Silt Layer under Soil Mound Loading
}

\author{
Xue-zeng Liu, ${ }^{1}$ Yun-long Sang $\mathbb{D}^{2,3}$ Li-min Xin, ${ }^{2,4}$ Gang Shi, ${ }^{2}$ and Jian-Xun $\mathrm{Wu}^{2}$ \\ ${ }^{1}$ Tongji University, Shanghai 200092, China \\ ${ }^{2}$ Shanghai Tongyan Civil Engineering Technology Co.,Ltd., Shanghai 200092, China \\ ${ }^{3}$ Civil Engineering Center of Ministry of Education Information Technology, Shanghai 200092, China \\ ${ }^{4}$ Shanghai Engineering Research Center of Underground Infrastructure Detection and Maintenance Equipment, \\ Shanghai 200092, China \\ Correspondence should be addressed to Yun-long Sang; hiker_1@163.com
}

Received 24 September 2019; Revised 3 April 2020; Accepted 9 May 2020; Published 29 May 2020

Academic Editor: Jiang Jin

Copyright ( 2020 Xue-zeng Liu et al. This is an open access article distributed under the Creative Commons Attribution License, which permits unrestricted use, distribution, and reproduction in any medium, provided the original work is properly cited.

Based on the structural damage of the shield tunnel caused by a soil mound on the ground surface in a section of subway in Tianjin, China, the deformation and the cracking process of the segment under soil mound loading were simulated. The variations of segment, bolt, and rebar stresses with the height of the mound were analyzed. The results show that, for the stagger-jointed assembled shield tunnel that crosses the marine sedimentary silt with a burial depth of $10 \mathrm{~m}$, as the mound loading increases, the damage is concentrated in the vault and hance. When the mound loading is $16.0 \mathrm{kPa}$, the segment is damaged; the crack depth and bolt axial force of the vault increase rapidly when the mound loading reaches $38.6 \mathrm{kPa}$. The analysis results are basically consistent with monitoring data. Based on the above analysis, the control standard of mound loading should be $38.6 \mathrm{kPa}$. The results of this study can provide data reference for control and structural protection of soil mound loading for similar subway tunnels.

\section{Introduction}

With the rapid development of urban infrastructure construction and the constant improvement of the rail transit network, different forms of new construction, e.g., soil piling, excavation, and crossing, have begun to appear in the vicinity of the subway, which has a certain impact on the tunnel structure in operation. Among them, the problem of structural safety hazards induced by soil mounds on the ground surface is prominent $[1,2]$. Huang [3] reported that abnormal settlement occurred within a section of $153 \mathrm{~m}$ of a subway in Guangzhou due to mound loading in the year 2013. In 2014, there were as many as 16 sudden soil piling events along the Shanghai subway, China, of which the maximum height of the mound above a certain section reached $7 \mathrm{~m}$, resulting in a maximum horizontal expansion of the structure exceeding $21 \mathrm{~cm}$, the collapse of the concrete block of the vault, and fracture of the partial bolt [1]. Therefore, exploring the deformation and damage process of tunnels under the action of soil mounds is of great significance to proposing reasonable standards to control soil mounds and effectively coping with disease caused by soil mounds.

Among currently available studies on soil mound loading, Atkinson and Potts [4] used indoor model tests to study the distribution characteristics of the internal force of tunnel lining structures under uniform soil mound loading. Through model tests, $\mathrm{Wu}$ and $\mathrm{Du}$ [5] explored the relationship between tunnel deformation, burial depth, and mound position. According to these studies, for tunnels with a burial depth less than twice the diameter, the mound should be more than twice the diameter away from the center line of the tunnel. By conducting model tests and three-dimensional numerical analysis, Zhang et al. [6] found that the larger the compressive modulus across the soil layer, the smaller the impact of the mound on the tunnel. Hudoba [7] established a finite-element model to study the internal force and deformation of the existing tunnel structure under 
soil mound loading, and the research results are in good agreement with the actual situation when the vertical connection stiffness was relatively large. Ye [8] studied the relationship between tunnel settlement and soil mound loading and concluded that the tunnel settlement increased approximately linearly with increasing mound loading. According to Yang et al. [9], tunnel settlement is directly proportional to the range of soil mound loading. Based on the above results, the influence of a soil mound on the tunnel structure differs greatly with geological conditions and burial depths.

In this study, a subway tunnel section in Tianjin, China, was studied, which crossed the marine sedimentary silt layer with a burial depth of $10 \mathrm{~m}$. Extensive soil piling on the ground surface occurred above the tunnel during its operation period, which resulted in structural diseases, such as segment cracking, water leakage, faulting of slab ends, opening of joints, and separation of the track bed, posing great threats to the operational safety of the subway. With the stagger-jointed assembled shield tunnel crossing the marine sedimentary silt layer with a burial depth of $10 \mathrm{~m}$ as the research object, the structural disease caused by soil mounds was investigated through on-site monitoring. In addition, how the tunnel deformation and segment, bolt, and rebar stress vary as the height of the mound changes were analyzed, and the evolution mechanism of segment cracking and structural damage was revealed. Moreover, with the additional load on the ground surface as the index, a standard for controlling the mound was proposed, which is of certain reference value for the control of soil mounds above subway tunnels in similar geological conditions.

\section{Engineering Background and Disease Survey Results}

2.1. Engineering Background. Affected by the accumulation of the ancient Yellow River and the Haihe River, as well as the action of ocean dynamics, the field of the research object in this study mainly consists of alluvial plains and marine depositional plains in which marine sedimentary silt is widely distributed, so the subway tunnel is quite sensitive to soil mounds on the ground surface. With a burial depth of $8.1-10.4 \mathrm{~m}$ and a groundwater level of $1.5 \mathrm{~m}$, the tunnel in this section mainly crosses the silt layer, with the overlying soil layer being plain fill, clay, and silt (Figure 1). With an outer diameter of $6.2 \mathrm{~m}$, the tunnel comprised $35 \mathrm{~cm}$ thick C50-reinforced concrete segments, and HRB335 steel bars were used as the main reinforcement, with a ring width of $1.2 \mathrm{~m}$. Each ring of segments was stagger-jointed-assembled, including three standard blocks, two adjacent blocks, and one top block. M30 bolts were used as the circumferential and longitudinal connecting bolts, with their grade being 5.8, and the segment structure is shown in Figure 2. As shown in Figure 3, the soil mound mainly ranges from $\mathrm{K} 2+800$ to $\mathrm{K} 2+913$, with a height of $8 \mathrm{~m}$.

2.2. Inspection of Structural Disease under Soil Mound Loading. According to on-site monitoring and testing data, the tunnel bore a large additional load from the mound above, which led to various diseases, such as structural deformation, cracking, water leakage, opening of joints, and faulting of slab ends. Moreover, the section from K2 +843 to $\mathrm{K} 2+903$ faced much more severe structural disease than other sections. A distribution of the diseases is shown in Figure 4.

2.2.1. Deformation and Settlement. The structure of the section from $\mathrm{K} 2+850$ to $\mathrm{K} 2+900$ was deformed, with a maximum horizontal deformation of $9.6 \mathrm{~cm}$ located in the $\mathrm{K} 2+878$ section. The deformation of the nondamaged section in the distance was basically $2 \sim 4 \mathrm{~cm}$. It can be considered that the horizontal expansion caused by the load was $5.6-7.6 \mathrm{~cm}$, and the tunnel settlement of this section was also the largest $(11.3 \mathrm{~cm})$ (Figure 5(a)).

2.2.2. Cracking. As shown in Figure 5(b), a large number of longitudinal cracks were formed in the adjacent arc blocks of the section from $\mathrm{K} 2+850$ to $\mathrm{K} 2+895$ and penetrated the entire ring of segments in the axial direction. The crack depth was $5-15 \mathrm{~cm}$, with the largest depth located in the vault of $\mathrm{K} 2+875$, whereas the cracks in the nondamaged section were not developed.

2.2.3. Opening of Joints and Faulting of Slab Ends. In the section from $\mathrm{K} 2+861$ to $\mathrm{K} 2+903$, obvious signs of intrusion were found in the top blocks (Figure 4). The maximum opening of longitudinal joints was $12 \mathrm{~mm}$, and the maximum faulting of slab ends of longitudinal joints reached $11.0 \mathrm{~mm}$, while the opening of longitudinal joints and faulting of slab ends in the nondamaged section were approximately $8.5 \mathrm{~mm}$ and $6.5 \mathrm{~mm}$, respectively. It can thus be seen that, in this section, the opening of longitudinal joints and faulting of slab ends were increased by 3.5 and $4.5 \mathrm{~mm}$, respectively, due to the mound (Figure 5(c)).

2.2.4. Water Leakage. It can be inferred that the mound not only caused obvious joint deformation in the vault but also led to a large joint deformation on the external side of the hance, resulting in a decrease in the waterproof performance of the joints and the risk of water leakage. It was found that there was intensive water leakage damage in the hance and arc bottom of the section from $\mathrm{K} 2+846$ to $\mathrm{K} 2+903$, and some of them were accompanied by sand leakage, which was consistent with the joint deformation (Figure 4).

The inspection results show that the subway tunnel suffered from extremely severe damage under the mound. Studies by some researchers show that opening of joints and water leakage will reduce the strength of the structure and may change the stress state of the tunnel $[10,11]$. In the extreme, water leakage may cope with soil erosion and lead to geotechnical hazards [12].

Based on this, the stress, deformation characteristics, and damage evolution mechanism of the tunnel under the mound loading were numerically analyzed, the field measurement and calculation analysis results were compared, 


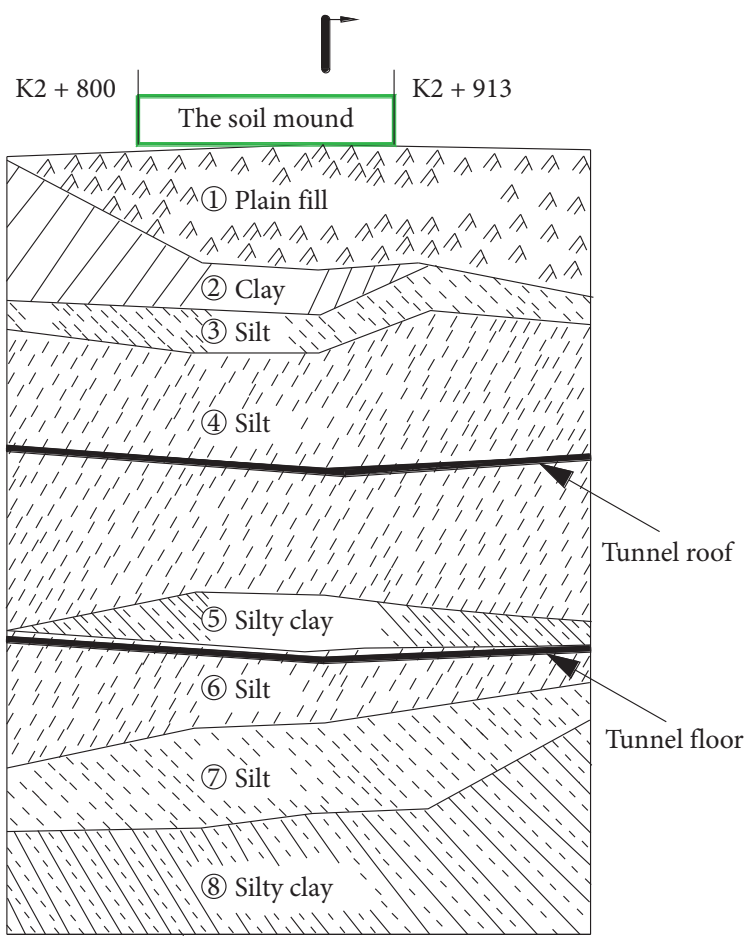

(a)

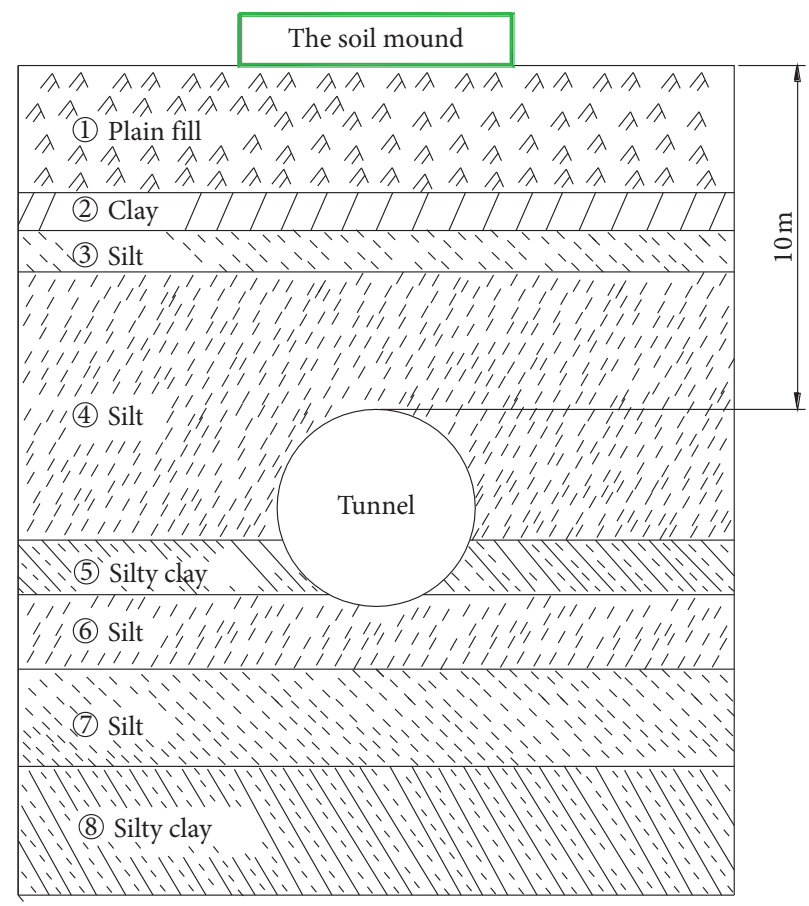

(b)

Figure 1: Geological profile of the soil mound area. (a) Vertical section. (b) Cross section.

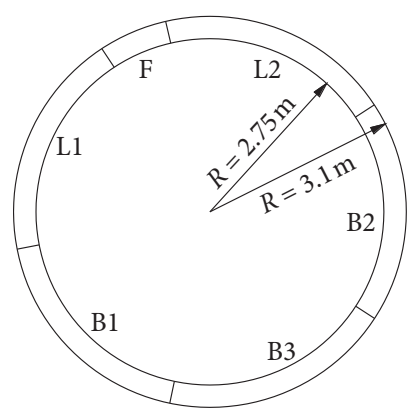

Figure 2: Segment structure.

and the standard of controlling soil piling on ground surface was proposed.

\section{Structural State of the Tunnel under Soil Mound Loading}

3.1. Analysis Method. In this study, a three-dimensional finite-element model was established, including the stratum, mound, tunnel, bolt, and rebar. To simplify the calculation, based on the field test results, the section from $\mathrm{K} 2+873$ to $\mathrm{K} 2+885$, i.e., the most severely damaged section, was analyzed. Ten rings were extracted in the axial direction to be used in the modeling (Figure 6). The tunnel segment and the soil and the mound above were meshed with hexahedral solid elements. The bolts and the rebars in the segment were meshed with beam elements. Friction contact was set

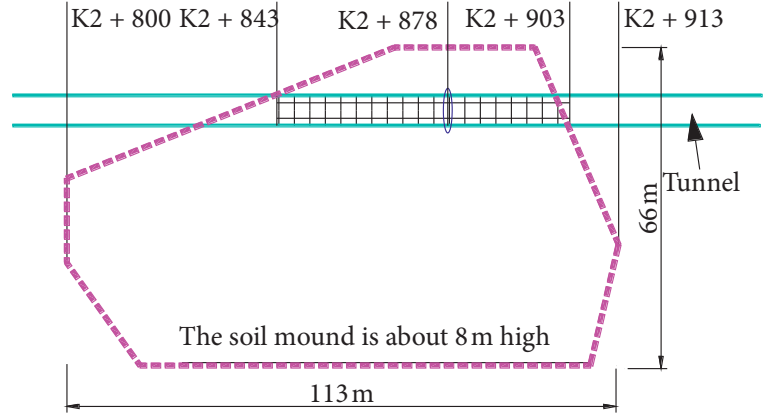

0 Max deformation of tunnel profile

围 Severe damage area

| Outer contour of the soil mound

Figure 3: Location and scope of the soil mound and tunnel.

between the segments, and a tie constraint was used between the segments and the soil. The displacement in the $Z$ direction of the bottom surface was constrained, the displacement in the $X$ direction was constrained for the left and right sides, and the displacement in the $Y$ direction was constrained for the front and back.

According to the research objectives, the D-P constitutive model was applied for the soil, the plastic damage constitutive model was adopted for the segments, the elastoplastic model was used for the bolts and rebars, hard contact was used for the contact in the normal direction, and 

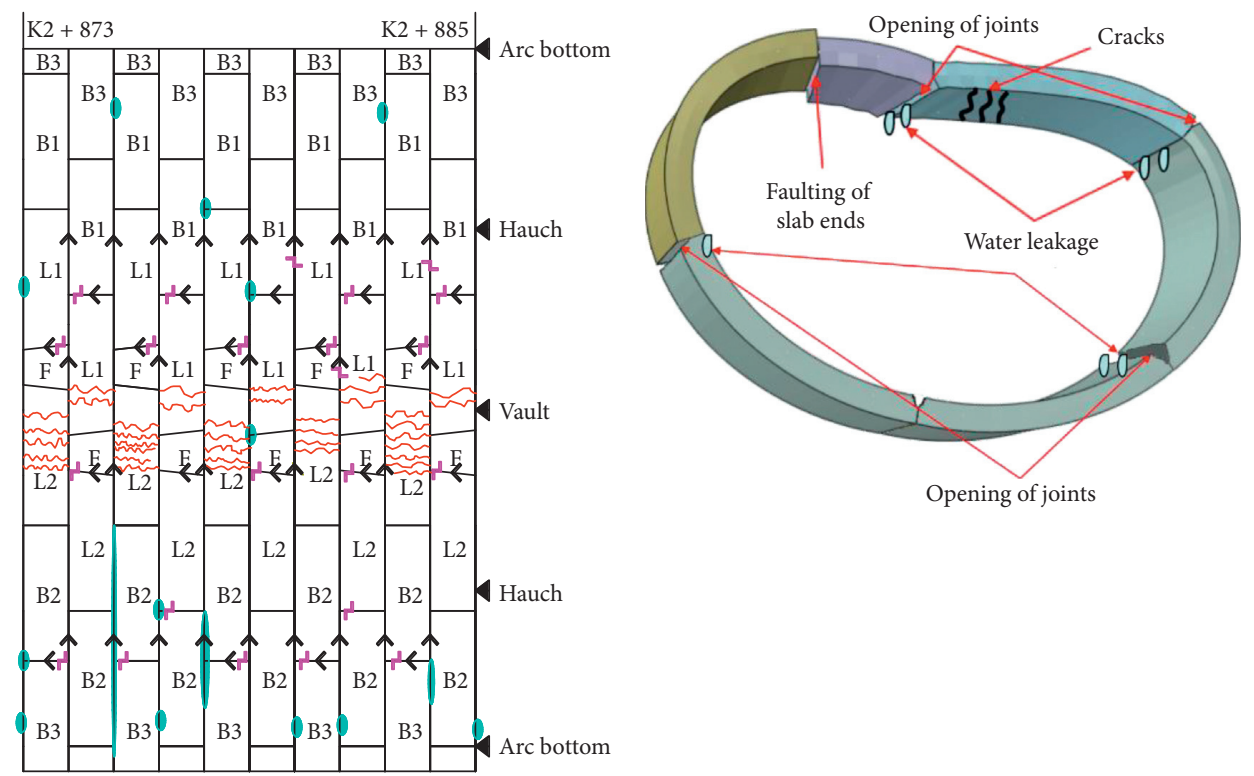

$\begin{array}{lll}\text { Disease legend } & & \\ \text { Water leakage } & \wedge & \text { Opening of joints } \\ \text { Crack } & \llcorner & \text { Faulting of slab end }\end{array}$

(a)

(b)

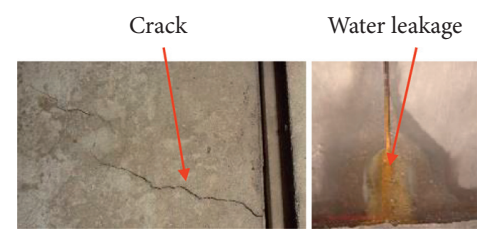

(c)

Figure 4: Layout and sketches of tunnel disease. (a) Layout of main disease in section K2 + 873 K2 + 885. (b) Distribution of tunnel damage. (c) Typical disease of tunnel.

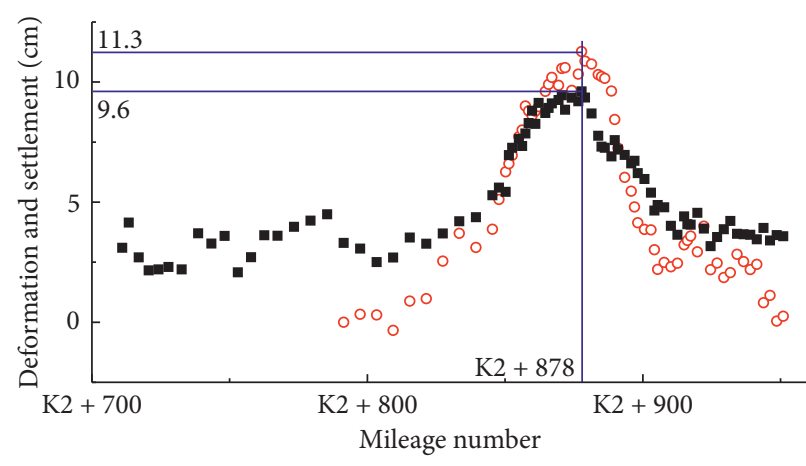

- Test data of tunnel settlement

- Test data of horizontal deformation of tunnel

(a)

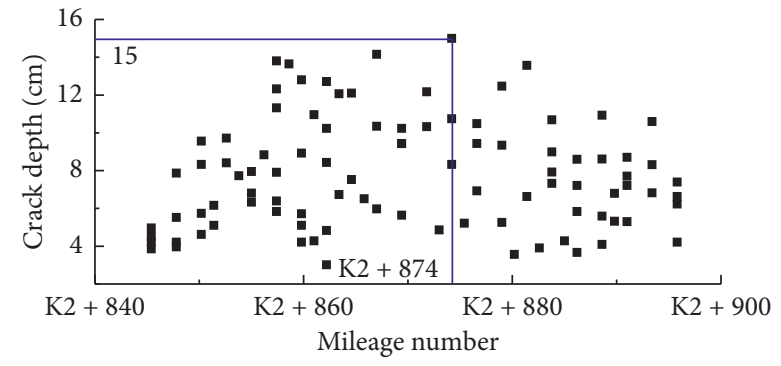

- Test data of crack depth

Faulting of slab end

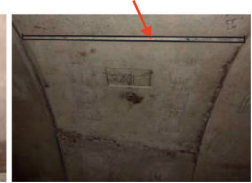




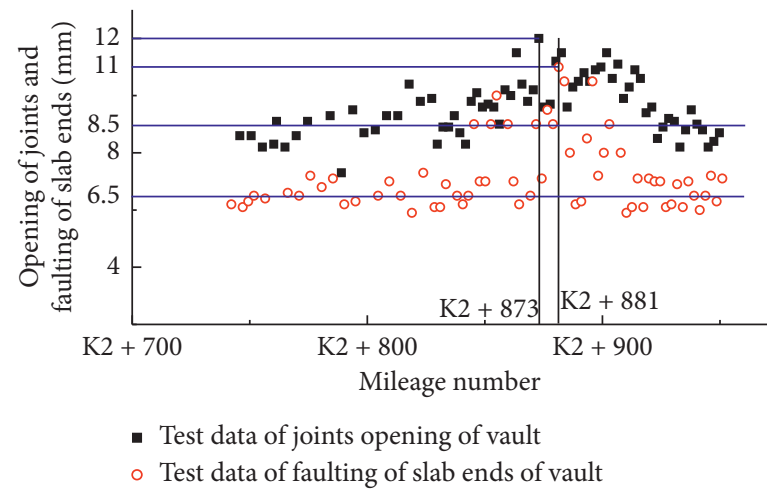

(c)

Figure 5: Testing data of the tunnel. (a) Test data of tunnel deformation and settlement. (b) Test data of crack depth. (c) Test data of opening of joints and faulting of slab ends.

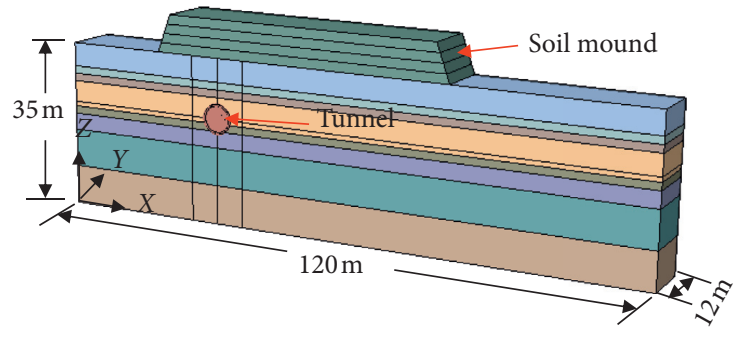

(a)

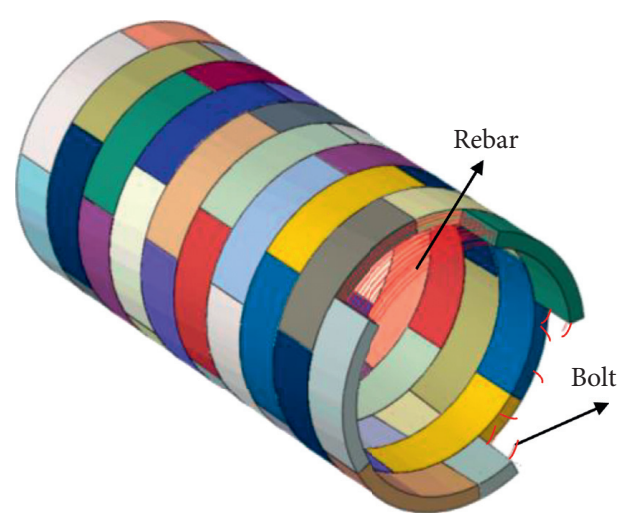

(b)

Figure 6: The computational model. (a) The whole model. (b) The tunnel model.

friction contact was used in the tangential direction with a friction coefficient of 0.6 [13]. The physical and mechanical parameters of the soil layer were extracted from the detailed geotechnical investigation of Line 2 of Tianjin Underground Railway Project. The concrete, rebar, and bolt parameters were based on the Code for Design of Concrete Structure (GB 50010-2010) [14], and Table 1 shows the material parameters of the model.

The plastic damage constitutive model in Abaqus software was able to characterize the damage degree of the segment through the damage factor. As shown in Figure $7, \sigma_{t o}$ is the ultimate tensile strength of concrete and $\theta$ is the damage factor. Before the tensile stress reaches the ultimate tensile strength, the damage factor is 0 ; when the concrete's strength fails, the damage factor becomes 1 .

After the model was constructed, the influence of the initial state was eliminated by balancing the crustal stress, and then, the influence of the mound height was simulated in increments of $0.01 \mathrm{~m}$ until it increased to $8 \mathrm{~m}$. The damage characteristics of structural deformation under mound loading were analyzed.
3.2. Evolution of Structural Damage of Segments under Soil Mound Loading. Figures 8-10 show that, as the mound height increases, the inside of the vault, the inside of the arch bottom, the outside of the right hance, and the outside of the left hance were damaged and cracked successively. In the initial state, the stress level of the segment was not high, and it was in the state of elastic stress without any damage on the surface. When the height of the mound reached $0.88 \mathrm{~m}$, damage first appeared in the vault and gradually expanded along the direction of the ring and the thickness of the segment. As the mound height reached $2 \mathrm{~m}$, the damage depth of adjacent blocks expanded to be 0.07 times the thickness of the segment, with the maximum damage factor reaching 0.22 . When the height continued to increase, a large range of damage zones appeared in the adjacent and top blocks of the vault, and damages were also found in the arch bottom, the right hance, and the left hance. When the mound was $6 \mathrm{~m}$ high, the damage factor of the arch reached 0.89 , with the damage depth being about half the thickness of the segment. When the mound height reached $8 \mathrm{~m}$, the damage factor of the arch was 1 , indicating that the concrete at the arch was ineffective. 
TABLE 1: Material parameters.

\begin{tabular}{|c|c|c|c|c|c|c|}
\hline Material & $\begin{array}{l}\text { Density } \\
\left(\mathrm{kg} / \mathrm{m}^{3}\right)\end{array}$ & $\begin{array}{c}\text { Elastic modulus } \\
(\mathrm{MPa})\end{array}$ & Poisson's ratio & Dilation angle $\left({ }^{\circ}\right)$ & Angle of friction $\left({ }^{\circ}\right)$ & Flow stress ratio \\
\hline Mound soil layer(1) & 1930 & 29.4 & 0.30 & 33.0 & 15.0 & 0.804 \\
\hline Miscellaneous fill soil layer(2) & 1940 & 30.6 & 0.30 & 33.0 & 15.0 & 0.804 \\
\hline Clay soil layer(3) & 1930 & 26.0 & 0.43 & 36.2 & 19.0 & 0.804 \\
\hline Silt soil layer(4) & 1930 & 17.3 & 0.41 & 27.8 & 14.0 & 0.85 \\
\hline Silt soil layer(5) & 1920 & 16.0 & 0.39 & 41.9 & 23.0 & 0.78 \\
\hline Silty clay soil layer (6) & 2020 & 29.4 & 0.41 & 43.3 & 24.0 & 0.78 \\
\hline Silt soil layer (7) & 2020 & 25.6 & 0.33 & 45.8 & 26.0 & 0.78 \\
\hline Silt soil layer(8) & 1940 & 23.7 & 0.31 & 34.6 & 18.0 & 0.81 \\
\hline Silty clay & 1930 & 27.1 & 0.35 & 34.0 & 17.8 & 0.81 \\
\hline Concrete & 2500 & $34.5 \times 10^{3}$ & 0.20 & - & - & - \\
\hline Bolt/rebar & 7850 & $2.0 \times 10^{5}$ & 0.30 & - & - & - \\
\hline
\end{tabular}

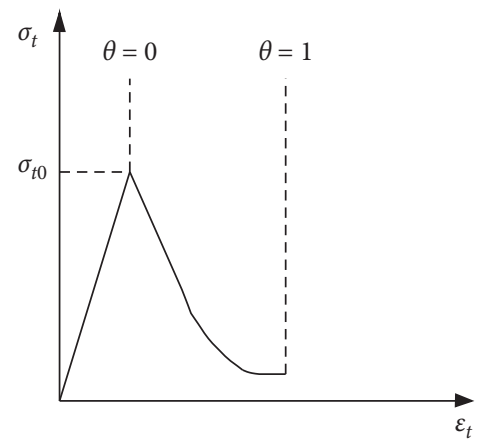

FIgURE 7: Relationship between damage factor and concrete stress-strain curve.
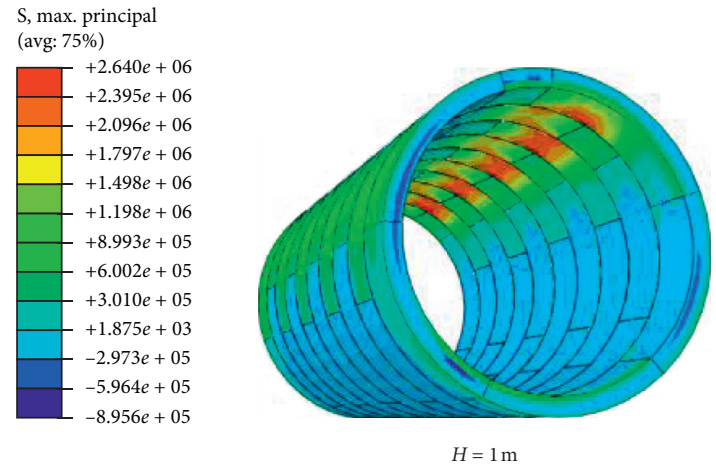

(a)

S, max. principal (avg: $75 \%$ )

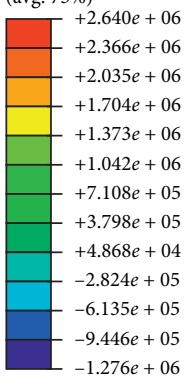

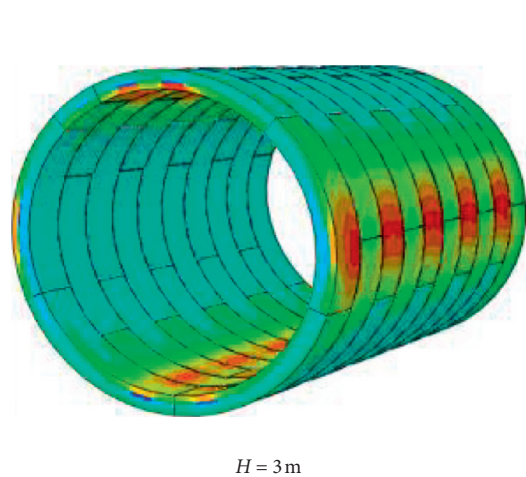

(c)
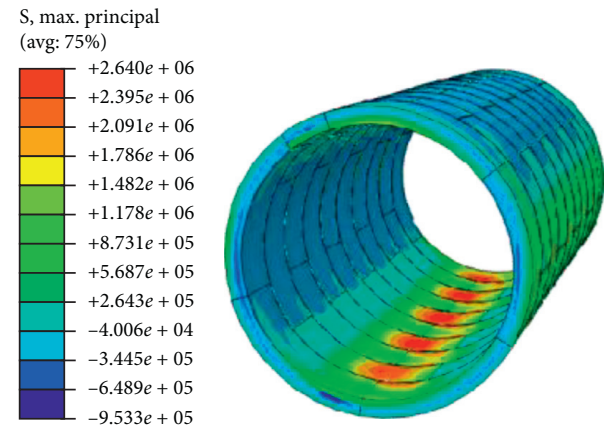

(b)

S, max. principal (avg: $75 \%$ )
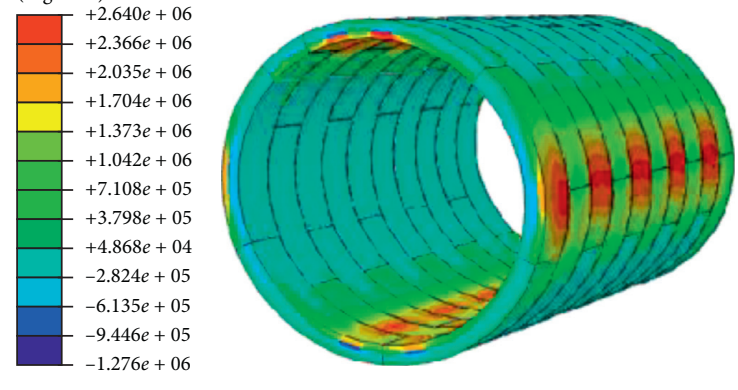

$H=4 \mathrm{~m}$

(d)

Figure 8: Development of concrete stress. $H$ represents the height of soil mound. 


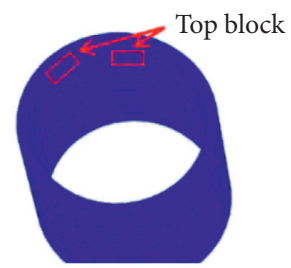

Initial status $(H=0 \mathrm{~m})$

Damage appears
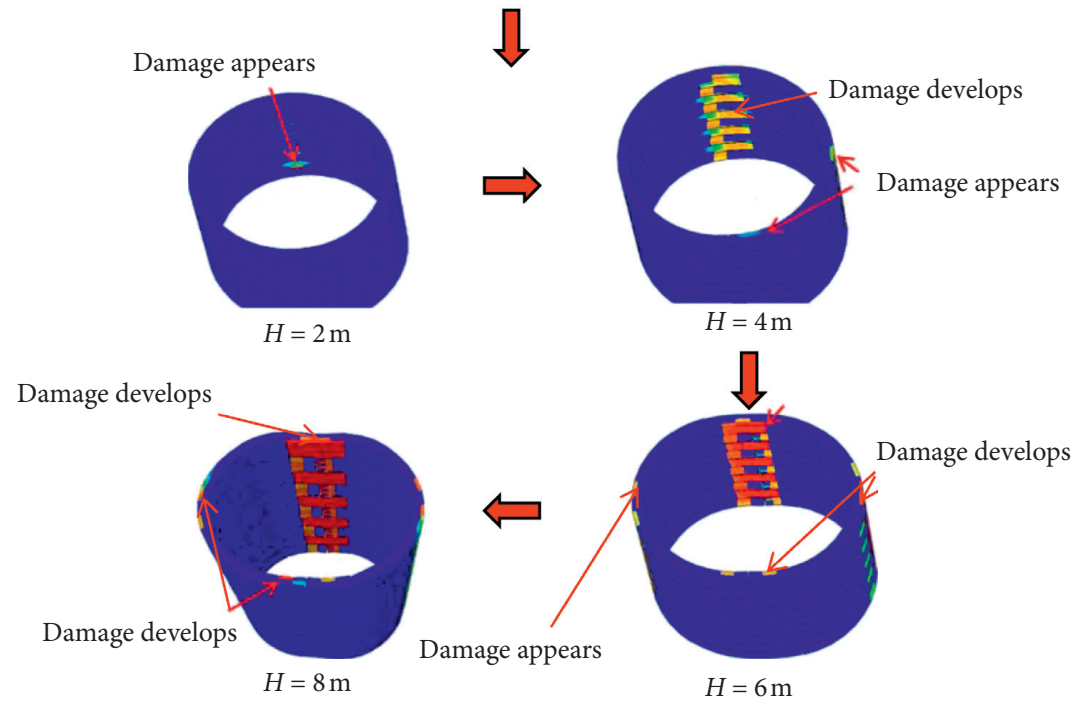

FIgURE 9: Development process of concrete damage with the mound height. $H$ represents the height of soil mound.

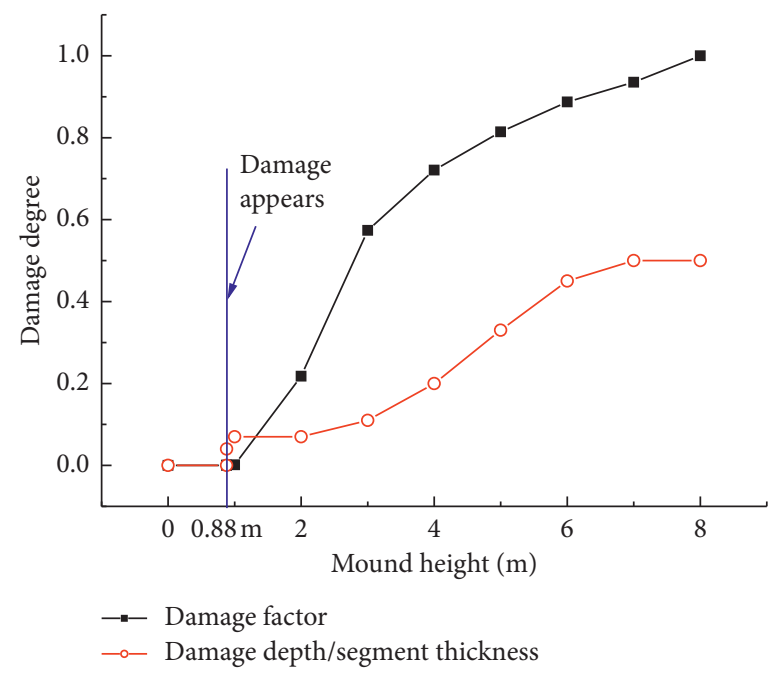

FIgURE 10: Damage status of vault concrete with the mound height.

The maximum tensile stress criterion was used to determine whether the segment was cracked; the crack width $w$ was calculated using Equation (1) (see Code for Design of Concrete Structure (GB 50010-2010) [14] for details on the physical meaning of each parameter), and the development process of the depth and width of the main crack of the vault was analyzed (Figure 10):

$$
w_{\max }=\alpha_{c r} \psi \frac{\sigma_{s}}{E_{s}}\left(1.9 c_{s}+0.08 \frac{d_{e q}}{\rho_{t e}}\right) .
$$

It can be seen from Figure 11 that the depth and width of the main crack of the vault basically share the same development trend with that of the damage factor. When the mound was $0.88 \mathrm{~m}$ high, a crack occurred in the segment; when the height of the mound reached $1 \mathrm{~m}$, the crack ran through the entire ring of segments in the axial direction, with the depth increasing to $2.5 \mathrm{~cm}$; as the mound height increased, the crack rapidly expanded longitudinally and the crack depth increased to $17.5 \mathrm{~cm}$ as the height reached $6.7 \mathrm{~m}$. According to the results of on-site inspection, the maximum 


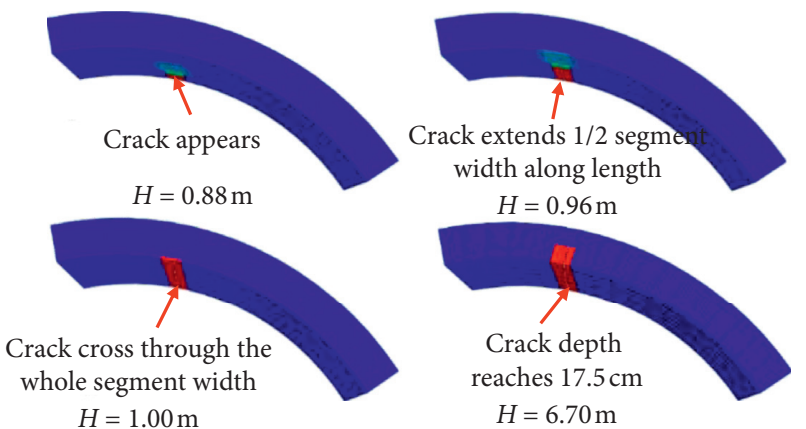

(a)

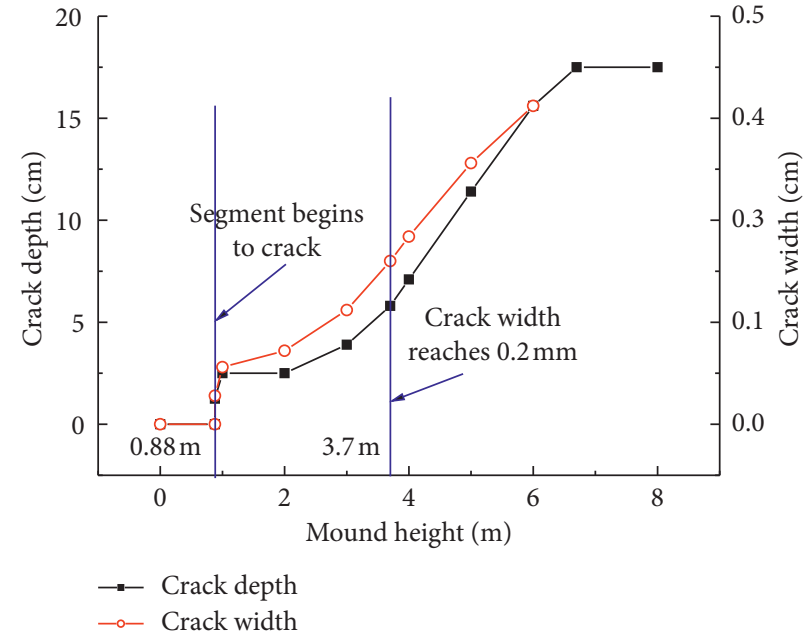

(b)

FIgURE 11: Development law of typical crack in segment vault with the mound height. (a) Development process of typical crack. $H$ represents the height of soil mound. (b) Development of depth and width of typical crack. Note: according to Code for Design of Metro (GB 50157-2013) [15], the allowable crack width is $0.2 \mathrm{~mm}$ when the calculated method is used.

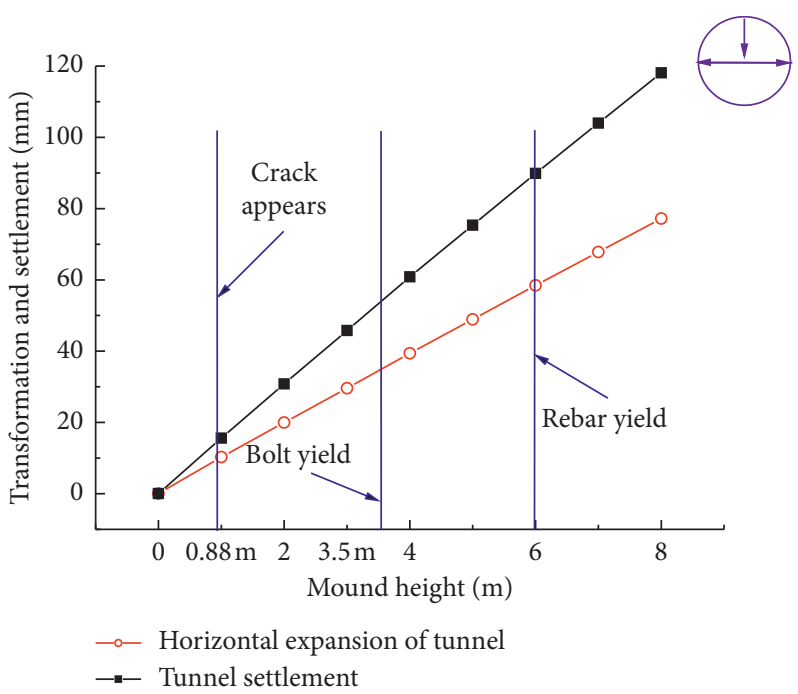

Figure 12: Development of tunnel deformation and settlement with the mound height.

depth of the vault crack was $15 \mathrm{~cm}$, which is in good agreement with the simulation results.

The analysis shows that the cracking damage on the inner side of the vault and the external side of the hance is relatively severe under mound loading. According to the results of on-site inspection, the cracks in the adjacent blocks of the vault were relatively developed, and the water leakage in the hance was prominent. The test results are in good agreement with the numerical analysis results, which verifies the rationality of the above calculation method.

3.3. Influence of Soil Mound on Deformation of Structure and Joints. Figure 12 shows the development process of the structural deformation under the mound (the arrows in
Figure 12 indicate positive structural deformation and settlement).

Under mound loading, the tunnel settlement and deformation increased linearly. When the height of the mound reached $8 \mathrm{~m}$, the horizontal expansion was $7.7 \mathrm{~cm}$ and the settlement of the vault was $11.8 \mathrm{~cm}$.

Affected by the mound above, obvious opening of longitudinal joints and faulting of slab ends in the vault occurred, and both increased linearly as the height of the mound increased (Figures 13 and 14). Before the soil was piled up, the maximum opening of longitudinal joints of the vault was $1.3 \mathrm{~mm}$ and there was no obvious faulting of slab ends. When the mound was $5.8 \mathrm{~m}$ high, the opening of longitudinal joints of the top and adjacent blocks was $4 \mathrm{~mm}$, reaching the threshold allowed by the design, and the 


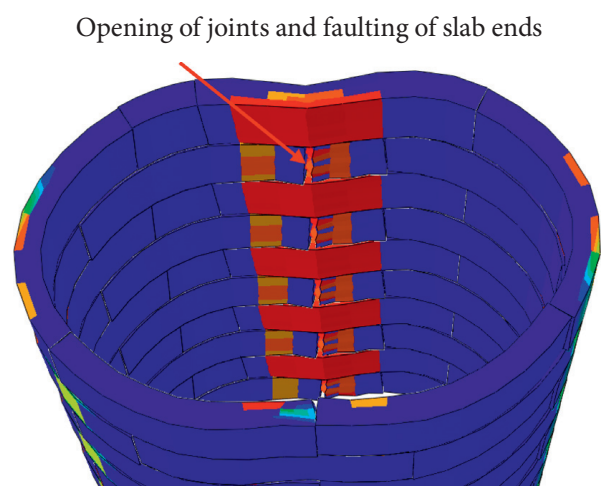

FIGURE 13: Opening of joints and faulting of slab ends.

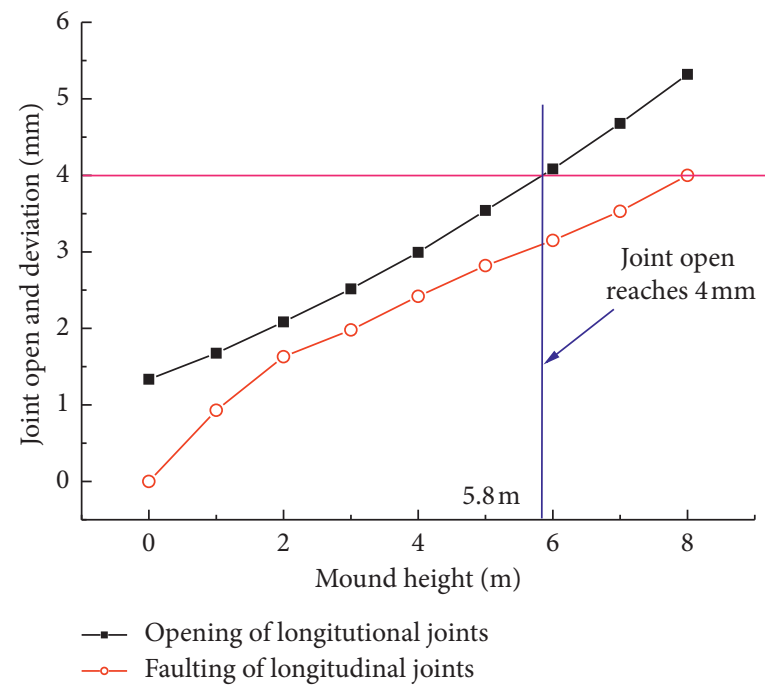

FIGURE 14: Development of opening and faulting of longitudinal joints.

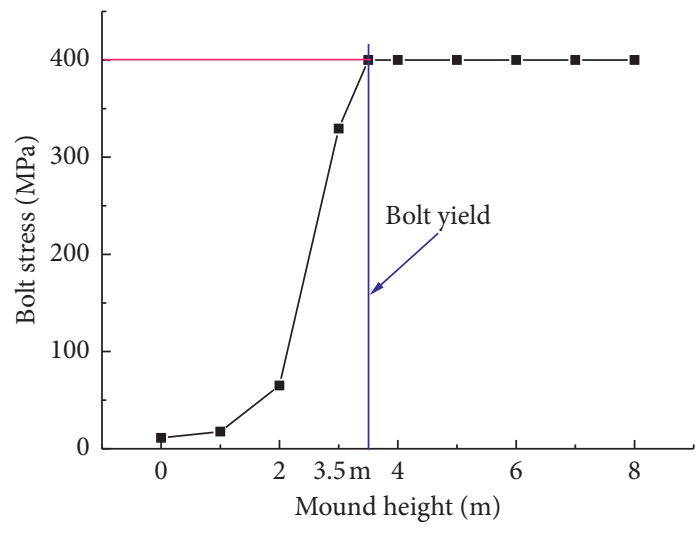

- Stress of circumferential bolt in segment vault

Figure 15: Stress-mound height curve of bolt in segment vault.

faulting of slab ends was $3.1 \mathrm{~mm}$. When the height of the mound was $8 \mathrm{~m}$, the opening of longitudinal joints reached $5.3 \mathrm{~mm}$ and the faulting of slab ends was approximately $4.0 \mathrm{~mm}$.
3.4. Influence of Soil Mound on Stress in Bolts and Rebars. The soil mound also has a great influence on the stress of joint bolts and on the steel bars. With the circumferential bolt between the top and adjacent blocks as the case study, as 


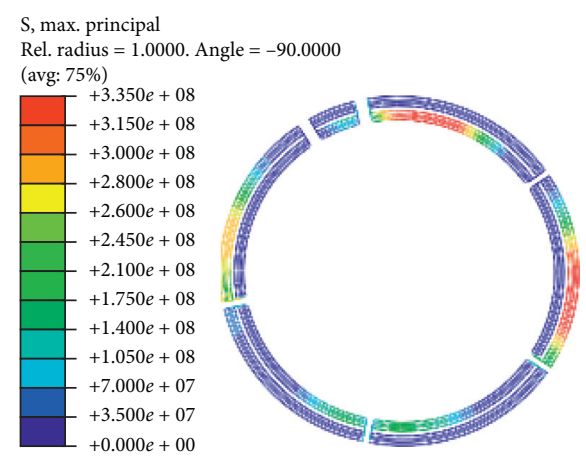

(a)

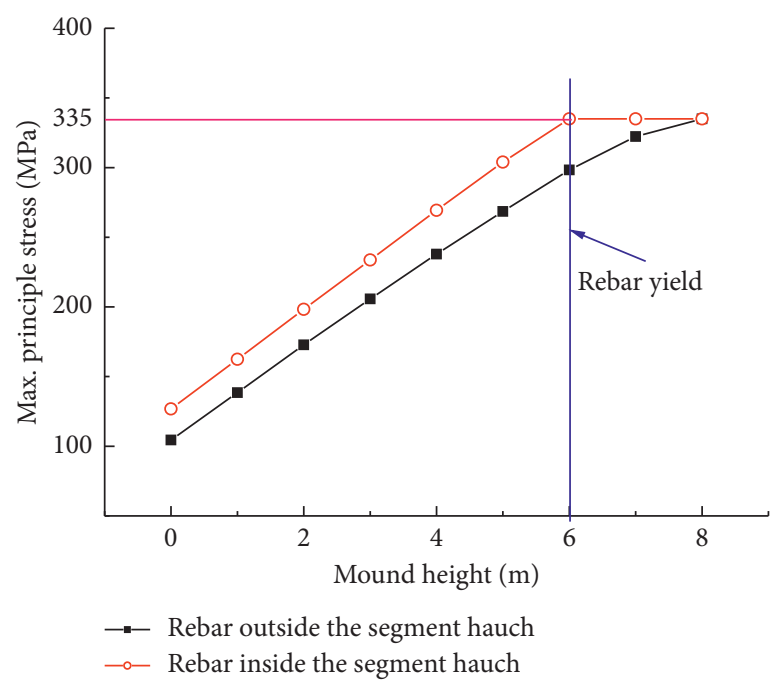

(b)

Figure 16: Maximum principal stress of rebar. (a) Maximum principal stress of rebar when mound height reached $8 \mathrm{~m}$. (b) Maximum principal stress-mound height curve of rebar.

shown in Figure 15, the stress was only $11 \mathrm{MPa}$ before the soil was piled up, which was much smaller than the yield strength. When the height of the mound was less than $2 \mathrm{~m}$, the bolt stress increased slowly, while once it reached more than $2 \mathrm{~m}$, the bolt stress began to increase rapidly and reached the yield strength when the mound was $3.5 \mathrm{~m}$ high.

Under the mound, the stress levels of the tensile rebars on the inner side of the vault and the external side of the hance were developed most significantly. As shown in Figure 16, the maximum principal stresses of rebar in the vault and the hance were 127 and $104 \mathrm{MPa}$, respectively, before the soil was piled up. The stress increased linearly as the mound height increased. When the height of the mound reached $6.0 \mathrm{~m}$, the rebar on the inner side of the vault was yielded by tension. When the height reached $8.0 \mathrm{~m}$, the rebar on the external side of the hance was yielded by tension.

According to the simulation results, the horizontal expansion of the segment caused by the mound was $7.7 \mathrm{~cm}$, the settlement of the vault was $11.8 \mathrm{~cm}$, the crack depth of the vault was $17.5 \mathrm{~cm}$, and the increment of both the opening of joints and faulting of slab ends was $4 \mathrm{~mm}$. On-site monitoring and test results show that, under the mound, the horizontal expansion of the segment increased by $7.6 \mathrm{~cm}$, the tunnel settlement was $11.3 \mathrm{~cm}$, the maximum crack depth was $15 \mathrm{~cm}$, and the maximum opening of joints and faulting of slab ends were 3.5 and $4.5 \mathrm{~mm}$, respectively. Thus, the simulation results are consistent with the field-measured data.

\section{Conclusions}

In this study, with a shield tunnel crossing a marine sedimentary silt layer with a burial depth of $10 \mathrm{~m}$ as the research object, based on on-site monitoring, detection, and numerical simulation, the processes of structural deformation and damage under the soil mounds on the ground surface were explored, and data of structural deformation, cracking, opening of joints, and bolt axial force under different mound heights were obtained, which revealed the structural damage mechanism under the influence of the mound and presented the standard of controlling soil piling on the ground surface. The main conclusions are as follows:

(1) Under the soil mound, the structural deformation, rebar stress, and opening of joints increased linearly, whereas the concrete damage, crack depth and width, and bolt axial force developed nonlinearly. As the mound height increased, the vault, arch bottom, and the hance on both sides were damaged successively, with the damage of the vault being the most severe. When the mound height reached a certain value, the rebars and bolts on the inner side of the vault were pulled and yielded, indicating that the structure entered an accelerated stage of destruction.

(2) The volumetric weight of the mound on ground surface of the research object in this study, $r$, is $19.3 \mathrm{kPa}$, and when the height of the mound is $h$, the mound loading on the ground surface is $P=\mathrm{rh}=19.3 \mathrm{~h}$. When the mound height was less than $0.88 \mathrm{~m}$, the segment was still in a safe state without any damage. When the height was $1 \mathrm{~m}$, the segment was damaged and cracked, and the cracks rapidly ran through the entire ring of segments in the longitudinal direction. When the height was less than $2 \mathrm{~m}$, the structural deformation and opening of joints were not that obvious, and the damage depth of the segment in the vault was only 0.07 times the thickness of the segment. As the height reached more than $2 \mathrm{~m}$, the crack depth and bolt stress rapidly increased, and the bolt was yielded by tension when the mound was $3.5 \mathrm{~m}$ high. When the height ranged from 3.5 to $8 \mathrm{~m}$, the tensile rebars in the vault and hance were yielded successively, and the opening of joints in the vault exceeded the $4 \mathrm{~mm}$ required by the 
design code. When the mound was $8 \mathrm{~m}$ high, the main crack of the vault was $17.5 \mathrm{~cm}$ deep, the opening of longitudinal joints was $5.3 \mathrm{~mm}$, the faulting of slab ends reached $4 \mathrm{~mm}$, both the bolts and tensile rebars reached the yield strength, and the vertical convergence and horizontal expansion were 7.4 and $7.7 \mathrm{~cm}$, respectively. The numerical simulation data were basically consistent with on-site test data.

(3) Once the mound height exceeded $2 \mathrm{~m}$, the cracks in the segment developed relatively obviously, and the bolt stress also began to increase rapidly. Therefore, for the tunnel studied here, it is recommended that the mound height should be controlled below $2 \mathrm{~m}$; that is, the mound loading on the ground surface should not exceed $38.6 \mathrm{kPa}$.

\section{Data Availability}

All data, model, and code generated or used during the study are included within the article and are available from the corresponding author upon request.

\section{Conflicts of Interest}

The authors declare that there are no conflicts of interest regarding the publication of this paper.

\section{Acknowledgments}

This study was supported by the National Basic Research Program of China (973 Program) (grant number: 2015CB057806), the National Natural Science Foundation of China (grant number: 51878497), the Xiamen Science and Technology Major Project (grant number: 3502Z20151006), and the Science and Technology Project of State Grid Corporation of China (grant number: SHJJGC160053).

\section{References}

[1] H. Shao, H. W. Huang, D. M. Zhang, and R. L. Wang, "Case study on repair work for excessively deformed shield tunnel under accidental surface surcharge in soft clay," Chinese Journal of Geotechnical Engineering, vol. 38, no. 6, pp. 10361043, 2016, in Chinese.

[2] X. J. Wei, H. W. Hong, G. Wei, and G. H. Yu, "Rotation and shearing dislocation deformation of subway tunnels due to adjacent ground stack load," Chinese Journal of Rock Mechanics and Engineering, vol. 37, no. 5, pp. 1281-1289, 2018, in Chinese.

[3] Y. Huang, "Subway tunnel operation risk analysis and treatment measures after surcharge on the surface," Construction Security, vol. 33, no. 8, pp. 58-60, 2015, in Chinese.

[4] J. H. Atkinson and D. M. Potts, "Stability of a shallow circular tunnel in cohesionless soil," Géotechnique, vol. 27, no. 2, pp. 203-215, 1977.

[5] Q. Wu and S. J. Du, "Model test on influence of ground heaped load on existing shield tunnel structure," Chinese Journal of Underground Space and Engineering, vol. 10, no. 1, pp. 57-66, 2014, in Chinese.
[6] M. G. Zhang, S. H. Zhou, D. W. Huang, X. Z. Wu, and H. B. Liu, "Analysis of influence of surface surcharge on subway shield tunnel under," Rock and Soil Mechanics, vol. 37, no. 8, pp. 2271-2278, 2016, in Chinese.

[7] I. Hudoba, "Contribution to static analysis of load-bearing concrete tunnel lining built by shield-driven technology," Tunnelling and Underground Space Technology, vol. 12, no. 1, pp. 55-58, 1997.

[8] Y. D. Ye, Research on Deformation and Method of Health Diagnose of Operational Subway Structures in Soft Soil, Tongji University, Shanghai, China, 2007, in Chinese.

[9] Q. Yang, D. L. Zhang, and Z. C. Liu, "Numerical simulations of longitudinal settlement of shield tunnel under local loading," Journal of Beijing University of Technology, vol. 38, no. 8, pp. 1220-1224, 2012, in Chinese.

[10] C. J. Gong, W. Q. Ding, and K. M. Mosalam, "Performancebased design of joint waterproofing of segmental tunnel linings using hybrid computational/experimental procedures," Tunnelling and Underground Space Technology, vol. 96, Article ID 103172, 2020.

[11] W. Ding, C. Gong, K. M. Mosalam, and K. Soga, "Development and application of the integrated sealant test apparatus for sealing gaskets in tunnel segmental joints," Tunnelling and Underground Space Technology, vol. 63, pp. 54-68, 2017.

[12] C. J. Gong, W. Q. Ding, and D. W. Xie, "Parametric investigation on the sealant behavior of tunnel segmental joints under water pressurization," Tunnelling and Underground Space Technology, vol. 97, Article ID 103231, 2020.

[13] F. Q. Chen, W. Tian, Z. G. Liu, and Z. K. Zhang, "Experimental study on friction coefficient of concrete with matching pouring surface," China Harbour Engineering, vol. 202, no. 12, pp. 34-38, 2014, in Chinese.

[14] GB 50010-2010, Code for Design of Concrete Structure, China Architecture \& Building Press, Beijing, China, 2015, in Chinese.

[15] GB 50157-2013, Code for Design of Metro, China Architecture \& Building Press, Beijing, China, 2014, in Chinese. 